\title{
Risk Factors and Subtyping of Ischemic Stroke in Young Adults in the Indian Population
}

\author{
Vishali Moond $^{1}$, Kannu Bansal ${ }^{2}$, Rohit Jain ${ }^{3}$ \\ 1. Internal Medicine, University College of Medical Sciences, New Delhi, IND 2. Internal Medicine, All India Institute of \\ Medical Sciences, New Delhi, IND 3. Internal Medicine, Penn State Health Hershey Medical Center, Hershey, USA
}

Corresponding author: Vishali Moond, vishali.moond@gmail.com

\begin{abstract}
Objective: To evaluate the risk factors and etiological subtyping of ischemic stroke in young adults in the Indian population.

Methods: This is a retrospective study of 160 patients, in the age group of 18 to 45 years with ischemic stroke, registered at a tertiary care hospital in Delhi, India between March 2014 and January 2018. Hypertension, diabetes mellitus, dyslipidemia, smoking, alcohol consumption, previous history of stroke, valvular heart disease, coronary artery disease (CAD), atrial fibrillation, family history, and migraine were considered as the identifiable risk factors. Stroke subtyping was done according to the Trial of Org 10172 in Acute Stroke Treatment (TOAST) criteria.
\end{abstract}

Results: The mean age of the patients was 36.2 years with $74 \%$ being males. Headache, vomiting, difficulty in speech, and hemiparesis were the common complaints at presentation. Common risk factors identified were hypertension (50\%), prior stroke or transient ischemic attack (TIA; $32 \%$ ), dyslipidemia (25\%), family history of stroke (18\%), and smoking (15\%). The most common TOAST subtype was undetermined (64\%), followed by other determined cause (ODC; 20\%), and cardioembolism (15\%).

Conclusion: There is a certain dissimilarity in the risk factors for ischemic stroke in young adults living in developing countries compared to those belonging to developed nations. Primary and secondary prevention targeted at the modifiable risk factors of ischemic stroke is necessary. Cerebral artery dissection, being a prevalent cause of ischemic stroke in young adults, should be carefully evaluated. A more appropriate stroke classification system specifically tailored for younger patients is needed.

Review began 10/15/2020 Review ended 10/30/2020 Published 11/09/2020

(c) Copyright 2020 Moond et al. This is an open access article distributed under the terms of the Creative Commons Attribution License CC-BY 4.0., which permits unrestricted use, distribution, and reproduction in any medium, provided the original author and source are credited.
Categories: Cardiology, Internal Medicine, Preventive Medicine

Keywords: risk factors, stroke subtyping, ischemic stroke, young adults, indian population

\section{Introduction}

Stroke is the leading cause of disability in adults and is the second most common cause of death worldwide. About two-thirds of stroke patients belong to developing countries [1]. In India and other developing countries, young adults constitute $15 \%-30 \%$ of all stroke patients as compared to $3 \%-8.5 \%$ in the West [2]. Young adults suffering from ischemic stroke have a larger bearing on the functioning of their family, society, and country as they are in their economically most productive period.

The causes of ischemic stroke in young adults are different than in the elderly. Also, careful evaluation of the stroke etiology is necessary for young adults to prevent recurrences.

Despite its significance, there is a scarcity of data on the risk factors and etiological subtyping of ischemic stroke in young adults in the Indian setting. We, through this study, aimed to fill this lacuna.

\section{Materials And Methods}

We retrospectively analyzed the data of 160 patients in the age group of 18 to 45 years with ischemic stroke registered at a tertiary care hospital in Delhi, India between March 2014 and January 2018. Ischemic stroke was defined as a sudden appearance of neurological signs and symptoms with imaging-confirmed cerebral infarction. Patients with intracranial hemorrhage, subarachnoid hemorrhage, and cerebral venous thrombosis were excluded.

Demographic, clinical and investigative data, and stroke risk factors were collected from the medical records. Investigations included hematological tests (complete blood count, blood sugar, serum cholesterol, serum triglyceride, prothrombin time, activated partial thromboplastin time), brain imaging (computerized tomography (CT), magnetic resonance imaging (MRI)), transthoracic echocardiography, and CT/MR angiography. 


\section{Cureus}

Hypertension, diabetes mellitus, dyslipidemia, smoking, alcohol consumption, previous history of stroke, valvular heart disease, coronary artery disease (CAD), atrial fibrillation, family history, and migraine were considered as risk factors for stroke. Stroke subtyping was done according to the Trial of Org 10172 in Acute Stroke Treatment (TOAST) criteria [3].

Data were entered into Microsoft Excel, and frequency and proportion were calculated.

\section{Results}

\section{Demographics}

The mean age of the patients was 36.2 years. Out of 160 patients, 118 (74\%) were males and 42 (26\%) were females.

\section{Symptoms and signs}

The symptoms and signs at presentation are depicted in Table 1.

\begin{tabular}{|l|l|}
\hline Signs and symptoms & Number of patients $(\mathbf{n}=\mathbf{1 6 0})$ \\
\hline Affection of speech & $96(60 \%)$ \\
\hline Right hemiparesis & $89(55 \%)$ \\
\hline Headache & $62(39 \%)$ \\
\hline Left hemiparesis & $47(30 \%)$ \\
\hline Vomiting & $40(25 \%)$ \\
\hline Loss of consciousness & $24(15 \%)$ \\
\hline Seizure & $16(10 \%)$ \\
Quadriparesis & $10(6 \%)$ \\
Carotid bruit & $4(2.5 \%)$
\end{tabular}

TABLE 1: Signs and symptoms at presentation

\section{Risk factors}

Risk factors identified were hypertension (50\%), prior stroke or transient ischemic attack (TIA; 32\%), dyslipidemia (25\%), family history of stroke (18\%), and smoking (15\%) (Table 2). 


\section{Cureus}

\begin{tabular}{|l|l|}
\hline Risk factor & Number o \\
\hline Hypertension & $80(50 \%)$ \\
Prior history of stroke & $51(32 \%)$ \\
Dyslipidemia & $41(25 \%)$ \\
Family history & $29(18 \%)$ \\
Smoking & $24(15 \%)$ \\
Diabetes mellitus & $19(12 \%)$ \\
Alcohol & $15(10 \%)$ \\
Valvular heart disease & $16(10 \%)$ \\
Atrial fibrillation & $13(8 \%)$ \\
Coronary artery disease & $11(7 \%)$ \\
Migraine & $5(3 \%)$ \\
\hline
\end{tabular}

\section{TABLE 2: Identified risk factors}

\section{Stroke subtype}

Stroke subtyping was done according to the TOAST criteria. The most common subtype was undetermined (64\%), followed by other determined cause (ODC; 20\%), and cardioembolism (15\%) (Table 3).

\begin{tabular}{|lc}
\hline Stroke subtype & Number of \\
\hline Incomplete evaluation & $157(98 \%)$ \\
Undetermined- Total & $102(64 \%)$ \\
Other determined causes & $32(20 \%)$ \\
Cardio-embolic & $24(15 \%)$ \\
Large artery atherosclerosis & $10(6 \%)$ \\
Small artery disease & $10(6 \%)$ \\
More than two etiologies & $5(3 \%)$
\end{tabular}

TABLE 3: Stroke subtyping according to Trial of Org 10172 in Acute Stroke Treatment (TOAST) criteria

\section{Discussion}

The majority (74\%) of our patients were males. This is in contrast to the findings of the studies in the West $[4,5]$. However, several studies conducted in India have shown similar male predominance [6,7]. This might be the result of a sociocultural referral bias in India due to which males are more likely to seek treatment at a tertiary care center.

The presenting features such as headache, vomiting, difficulty in speech, and hemiparesis were similar to the previous studies conducted in India [6,8].

Hypertension was found to be the most common risk factor followed by prior stroke or TIA. Dyslipidemia and family history of stroke were the other leading risk factors for ischemic stroke. Although smoking and alcohol were found in $15 \%$ and $10 \%$ of the patients respectively, they were still less frequent compared to the studies conducted in the developed countries $[9,10]$. Prior stroke being a major risk factor might be because of lack of awareness for secondary prevention of stroke and hence, non-compliance to medications in 
patients. Aggressive primary and secondary prevention targeted at the modifiable risk factors of ischemic stroke is needed [7].

The most common stroke subtype was found to be undetermined (64\%). This was significantly higher than the reported rate in the studies conducted in Western countries [11,12]. The possible reason behind this is the incomplete evaluation in the majority of our patients due to their unaffordability. Among ODC, cerebral artery dissection was reported to a prevalent cause of ischemic stroke in young adults and hence, its careful evaluation is necessary [13].

Cardioembolic stroke occurred in $15 \%$ of our patients. Valvular heart disease secondary to rheumatic heart disease (RHD) was its most common cause, as seen in the other studies conducted in the Indian setting $[6,7,14]$. In contrast to the studies conducted in the West, none of our patients were found to have patent foramen ovale, atrial septal aneurysm, or left atrial appendage thrombi [15]. This can be because we did not use transesophageal echocardiography (TEE) and hence, missed the diagnosis.

Five patients (3\%) in the current study had migraine. Sacco et al. stated that migraine (especially with aura) should be considered as a risk factor for ischemic stroke and TIA [16]. Relation of stroke with preceding infection has also been hypothesized [17].

Alebeek et al., in 2018, proposed for an appropriate stroke classification system specifically tailored for younger patients. They stated that such a classification system would help to identify risk factors in patients otherwise classified as "unknown etiology" according to TOAST classification [18].

Limitations of our study were retrospective design, lack of complete evaluation, and a small number of patients.

\section{Conclusions}

The current study highlights the dissimilarity between the developing and developed countries in the risk factors for ischemic stroke in young adults. History of prior stroke was found to be a major risk factor and hence, aggressive primary and secondary prevention targeted at the modifiable risk factors of ischemic stroke is needed. Cerebral artery dissection should be carefully evaluated in young patients with ischemic stroke. A more appropriate stroke classification system specifically tailored for younger patients is needed.

\section{Additional Information}

\section{Disclosures}

Human subjects: Consent was obtained by all participants in this study. Institutional Ethics Committee Human Research (IEC-HR) issued approval IEC/HR/2014/29/13. Your protocol submitted to IEC-HR on the topic "Risk Factors and Subtyping of Ischemic Stroke in Young Adults in the Indian Population" under the guidance of Dr. Rohit Jain has been approved by the committee in the meeting held on 2nd March 2017 in its present form. . Animal subjects: All authors have confirmed that this study did not involve animal subjects or tissue. Conflicts of interest: In compliance with the ICMJE uniform disclosure form, all authors declare the following: Payment/services info: All authors have declared that no financial support was received from any organization for the submitted work. Financial relationships: All authors have declared that they have no financial relationships at present or within the previous three years with any organizations that might have an interest in the submitted work. Other relationships: All authors have declared that there are no other relationships or activities that could appear to have influenced the submitted work.

\section{References}

1. Bonita R, Mendis S, Truelsen T, Bogousslavsky J, Toole J, Yatsu F: The global stroke initiative. Lancet Neurol. 2004, 3:391-3. 10.1016/S1474-4422(04)00800-2

2. Kaul S, Bandaru VC, Suvarna A, Boddu DB: Stroke burden and risk factors in developing countries with special reference to India. J Indian Med Assoc. 2009, 358:367-70.

3. Adams HP Jr, Bendixen BH, Kappelle LJ, Biller J, Love BB, Gordon DL, Marsh EE III: Classification of subtype of acute ischemic stroke. Definitions for use in a multicenter clinical trial. TOAST. Trial of Org 10172 in Acute Stroke Treatment. Stroke. 1993, 24:35-41. 10.1161/01.str.24.1.35

4. Ji R, Schwamm LH, Pervez MA, Singhal AB: Ischemic stroke and transient ischemic attack in young adults: risk factors, diagnostic yield, neuroimaging, and thrombolysis. JAMA Neurol. 2013, 70:51-57. 10.1001/jamaneurol.2013.575

5. Lisovoski F, Rousseaux P: Cerebral infarction in young people. A study of 148 patients with early cerebral angiography. J Neurol Neurosurg Psychiatry. 1991, 54:576-7. 10.1136/jnnp.54.7.576

6. Nayak SD, Nair M, Radhakrishnan K, Sarma PS: Ischaemic stroke in the young adult: clinical features, risk factors and outcome. Natl Med J India. 1997, 10:107-112.

7. Dash D, Bhashin A, Pandit AK, Tripathi M, Bhatia R, Prasad K, Padma MV: Risk factors and etiologies of ischemic strokes in young patients: a tertiary hospital study in north India. J Stroke. 2014, 16:173-7. 10.5853/jos.2014.16.3.173

8. Chopra JS. Prabhakar S: Clinical features and risk factors in stroke in young. Acta Neurol Scand. 1979, 


\section{Cureus}

60:289-300. 10.1111/j.1600-0404.1979.tb02984.x

9. Allen CL, Bayraktutan U: Risk factors for ischaemic stroke. Int J Stroke. 2008, 3:105-116. 10.1111/j.17474949.2008.00187.x

10. Hillbom M, Haapaniemi H, Juvela S, Palomäki H, Numminen H, Kaste M: Recent alcohol consumption, cigarette smoking and cerebral infarction in young adults. Stroke. 1995, 26:40-5. 10.1161/01.STR.26.1.40

11. Nedeltchev K, der Maur TA, Georgiadis D, et al.: Ischaemic stroke in young adults: predictors of outcome and recurrence. J Neurol Neurosurg Psychiatry. 2005, 76:191-195. 10.1136/jnnp.2004.040543

12. Rasura M, Spalloni A, Ferrari M, De Castro S, Patella R, Di Lisi F, Beccia M: A case series of young stroke in Rome. Eur J Neurol. 2006, 13:146-152. 10.1111/j.1468-1331.2006.01159.x

13. Schievink WI: Spontaneous dissection of the carotid and vertebral arteries . N Engl J Med. 2001, 345:467. 10.1056/NEJM200108093450616

14. Lipska K, Sylaja PN, Sarma PS, Thankappan KR, Kutty VR, Vasan RS, Radhakrishnan K: Risk factors for acute ischaemic stroke in young adults in South India. J Neurol Neurosurg Psychiatry. 2007, 78:959-963. 10.1136/innp.2006.106831

15. Putaala J, Metso AJ, Metso TM, et al.: Analysis of 1008 consecutive patients aged 15 to 49 with first-ever ischemic stroke. Stroke. 2009, 40:1195-1203. 10.1161/STROKEAHA.108.529883

16. Sacco S, Kurth T: Migraine and the risk for stroke and cardiovascular disease . Curr Cardiol Rep. 2014, 16:524. 10.1007/s11886-014-0524-1

17. Elmsley HCA, Hopkins SJ: Acute ischaemic stroke and infection: recent and emerging concepts . Lancet Neurol. 2008, 7:341-353. 10.1016/S1474-4422(08)70061-9

18. Alebeek ME, Arntz RM, Ekker MS, et al.: Risk factors and mechanisms of stroke in young adults: The FUTURE study. J Cereb Blood Flow Metab. 2018, 38:1631-1641. 10.1177/0271678X17707138 